\title{
The Effect of Benzophenone Photo-Initiator on Some Mechanical Properties of Photo-Oxidized Polypropylene / Thermoplastic Starch Blends
}

\author{
${ }^{*}$ O. E. Ezeani., ${ }^{2}$ I.O. Igwe., and ${ }^{3}$ G.N. Onyeagoro. \\ ${ }^{1,2, ~ \& ~}{ }^{3}$ Department of Polymer and Textile Engineering, Federal University of Technology, P.M.B 1526, Owerri, \\ Imo State, Nigeria.
}

\begin{abstract}
The effect of benzophenone photo-initiator on some mechanical properties of photo-oxidized polypropylene / thermoplastic starch blends has been investigated. Polypropylene-graft-maleic anhydride (PP-g-MA) was used as compatibilizer while benzophenone served as photo-initiator. The various polypropylene / thermoplastic starch blend samples were compounded in an injection moulding machine. The already weighed prepared blend samples were subjected to photo-oxidation in an open atmosphere to sunlight at an inclination angle of $45^{\circ} \mathrm{C}$ for a period of six (6) months at regular intervals of zero (0), three (3), and six (6) months during the dry season. The effect of benzophenone photo-initiator on the blends was evaluated by mechanical property measurements and weight losses. Experimental results obtained showed that the tensile strength, and extension at break of the photo-oxidized polypropylene / thermoplastic starch blended samples were found to decrease with increases in thermoplastic starch, and benzophenone content, while the impact strength, hardness, and weight losses of the blend samples increased with increases in the maleic- graft-anhydride polypropylene, and benzophenone contents as well as periods of exposure.
\end{abstract}

Keywords: Polypropylene, thermoplastic starch, benzophenone, and mechanical properties.

Date of Submission: 14 June 2016 Date of Accepted: 26 January 2017

\section{INTRODUCTION}

The increase in the production of commercial plastics, particularly commodity plastics (a significant amount of these plastic bags come from supermarkets, service stations, convenience, liquor and other retail stores) used in packaging and agriculture, and their lack of photo-oxidative degradation, have aroused public attention on a potentially huge environmental accumulation and pollution problem that could persist for centuries (Baljit and Nisha, 2008, Sharma et al., 2001). Polypropylene is a light weight material that has high tensile strength, low water absorption, and remains unaffected when it comes in contact with chemicals such as alkaline substances, de-greasing agents' e.t.c. (Cacciari et al., 1993). Several studies have been carried out on polypropylene degradation, and almost, all have been proven that polypropylene is an inert polymer that has good resistance to the action of sunlight and micro-organisms. To accelerate the degradation of polymers, biopolymers such as are frequently incorporated into the polymer, producing plastic films with a porous structure, which enhances the accessibility of the plastic to oxygen and micro-organism. Starch has received adequate attention in the preparation of photo-oxidative degradable plastics especially for one time use plastics. Starch is one of the most abundant, renewable and inexpensive natural biopolymers. Starch is produced by all green plants and consists of two distinct molecules, the amylase (linear polymer), and amylopectin (branched-polymer). The use of starch alone is not encouraging because of its lack of melt-processability and humidity resistance, which in turn militates against its suitability for extrusion or injection moulding (Wang et al., 2000, Nawang et al., 2001 and Abdul Khali et al., 2001). In order to improve the melt-processability of starch while also providing flexibility in the end-use product, plasticizers such as water, glycerol, sorbitol e.t.c are added to increase the fluidity or plasticity of the polymer. The production of thermoplastic starch (TPS) (also known as plasticizer starch, PS) basically involves the use of starch, a plasticizer, and source of thermo-mechanical energy. In thermoplastification of starch, the crystallinity collapses through the formation of hydrogen bonds between the plasticizer and starch in the presence of an energy source, invariably, severing the hydrogen bonds between the hydroxyl groups of the starch molecules to form thermoplastic starch (Yang et al., 2006). In packaging and agricultrural films, many attempts have focused on blending polypropylene and thermoplastic starch to enhance the degradability of the polymer (Ogah and Afiukwa, 2011). Polypropylene-graft-maleic anhydride (PP-g-MA) is the most common compatibilizer for polypropylene / thermoplastic starch blends. The maleic anhydride groups of polypropylene-graft-maleic anhydride react with the hydroxyl groups of starch while the 
polypropylene chains interact with the polypropylene matrix (Salmah et al., 2014, Park et al., 2006, Chun et al., 2013a and 2013b, and Pushpadass et al., 2009). However, the incorporation of photo-initiator in polymers is one of the mechanisms of photo-oxidative degradation of polymers. Photo-initiators are highly photosensitive and readily get excited on exposure to light, they initiate a reaction through the use of a substance capable of absorbing light, causing excitation, radical formation, oxygen addition, splitting off small molecules, chain scission e.t.c. Albertsson et al., (1992) examined the susceptibility of enhanced environmentally degradable polyethylene to thermal and photo-oxidation. The low density polyethylene films containing starch filler, prooxidant, and thermal stabilizer were subjected to accelerated thermal aging in an air environment at $60{ }^{\circ} \mathrm{C}$ and $100{ }^{\circ} \mathrm{C}$, and to UV ageing. The LDPE films containing corn starch as the sole additive was found not to be degraded, suggesting that the pro-oxidant formulation was responsible for the observed degradation. Omichi et al., (1979) evaluated photodegradable polyethylene film containing radiation-modified atactic polypropylene as a photosensitizer. The film was used indoors and outdoors as a protective cover for seedbeds of strawberry for half a year. The tensile strength and percent elongation of the film used indoors were maintained at $70-80 \%$ of the initial values whereas those used outdoors continuously decreased to $50-30 \%$ respectively.

In this present work, we report the study on the effect of benzophenone photo-initiator on some mechanical properties of photo-oxidized polypropylene / thermoplastic starch blends. This study has not been reported in the scientific literature to our knowledge.

\section{Materials}

\section{MATERIALS AND METHODS}

The Polypropylene used in this study was obtained from Indorama Petrochemical Eleme, River state, Nigeria. Polypropylene-graft-maleic anhydride (PP-g-MA) and benzophenone were purchased from Zigma Aldrich Netherland, and U.S.A respectively. The Cassava starch was obtained from Eke Awka market, Awka, Anambra State. The Glycerol (AR) was purchased from Lonover Scientific Supplies London and was used as received.

\section{Sample Preparation}

The cassava starch was sieved to $75 \mathrm{~mm}$ particle size using the sieving method and oven dried at $120{ }^{0} \mathrm{C}$ to a moisture content of less than $1 \%$ prior to sample preparations. Thermoplastic starch (TPS), also known as plasticized starch, was prepared from cassava starch. $300 \mathrm{~g}$ of cassava starch powder was mixed with $200 \mathrm{~g}$ of glycerol and $125 \mathrm{~g}$ of distilled water, and the mixture was stirred using a high speed mixer to give homogeneous slurry. The slurry once made was used immediately in the preparation of the polypropylene / thermoplastic starch blends.

\section{Polypropylene / Thermoplastic Starch Blends.}

The compositions of the various polypropylene / thermoplastic starch blend samples studied are shown in Table 2.3.1. The amount of thermoplastic starch (TPS) used in making the blends was based on the weight of polypropylene (PP) used, while that of polypropylene-graft- maleic anhydride (PP-g-MA) and photo-initiator (benzophenone) were based on the amount of thermoplastic starch (TPS) in the blends. Each of the blend samples containing varying amounts of polypropylene, thermoplastic starch, compatibilizer (maleic anhydridegraft-polypropylene), and photo-initiator (benzophone), was thoroughly mixed, melt-blended, and homogenized in an injection moulding machine. The polypropylene / thermoplastic starch blends were extruded as sheets. The already weighed prepared blend samples were subjected to photo-oxidation in an open atmosphere. Each of the blend samples was placed on a constructed wooden rack with a rack holder, and exposed to sunlight at an inclination angle of $45^{\circ} \mathrm{C}$ for a period of six (6) months at regular intervals of zero (0), three (3), and six (6) months during the dry season. The blend samples were removed from sunlight exposure so as to study the effects of natural weathering on the photo-oxidation of the blends. Each of the removed samples was weighed, and the weight loss was noted. Tensile testing was also used to determine the changes in the mechanical properties of the blended samples.

Table. 2.3.1. The composition of the polypropylene / thermoplastic starch blend samples.

\begin{tabular}{|l|c|c|c|c|}
\hline $\begin{array}{l}\text { Sample } \\
\text { code }\end{array}$ & $\begin{array}{c}\text { Polypropylene (PP) } \\
\text { (wt. \%) }\end{array}$ & $\begin{array}{c}\text { TPS } \\
\text { (wt. \% of PP) }\end{array}$ & $\begin{array}{c}\text { PP-g-MA } \\
\text { (wt. \% of TPS) }\end{array}$ & $\begin{array}{c}\text { Benzophenone } \\
\text { (wt. \% of TPS) }\end{array}$ \\
\hline Pure PP & 100 & - & & \\
\hline PT-1 & 98 & 2 & - & \\
\hline PT-2 & 95 & 5 & - & \\
\hline PT-3 & 90 & 10 & - & \\
\hline PT-4 & 80 & 20 & - & - \\
\hline PTC-1 & 98 & 2 & 20 & - \\
\hline PTC-2 & 95 & 5 & 20 & - \\
\hline PTC-3 & 90 & 10 & 20 & - \\
\hline PTC-4 & 80 & 20 & 20 & \\
\hline
\end{tabular}


The Effect Of Benzophenone Photo-Initiator On Some Mechanical Properties Of Photo-Oxidized...

\begin{tabular}{|l|l|l|l|l|}
\hline PTCB-1 & 98 & 2 & 20 & 20 \\
\hline PTCB-2 & 95 & 5 & 20 & 20 \\
\hline PTCB-3 & 90 & 10 & 20 & 20 \\
\hline PTCB-4 & 80 & 20 & 20 & 20 \\
\hline
\end{tabular}

\section{Mechanical Properties of Blends.}

The mechanical properties of the prepared blends were determined using standard methods. Tensile stress-strain measurements were performed using the Universal Testing Machine (UTM) Instron 1195 according to ASTM D638 from which the tensile strength and extension at break were determined. Impact strength (ASTM D 256), Brinell hardness (ASTM D 785), and weight losses of the blends were also determined.

\section{RESULTS AND DISCUSSIONS}

Effect of Thermoplastic Starch Content on the Mechanical Properties of Photo-oxidized Polypropylene / Thermoplastic Starch Blend Samples.

Data obtained on the effects of thermoplastic starch content and exposure time on the tensile strength, extension at break, impact strength, and hardness of the photo-oxidized polypropylene / thermoplastic starch blend samples are illustrated graphically as shown in Figures 4.1 to 4.4

From Figures 4.1 to 4.4, it is evident that pure polypropylene did not undergo photo-oxidation after 3 to 6 months of exposure to the atmosphere. This shows that polypropylene is stable to oxidative degradation. However, blend samples containing thermoplastic starch showed appreciable decrease in tensile strength which decreased with increase in exposure period. This is attributable to the micro-structure of the starch granules that are embedded in the polypropylene matrix. The
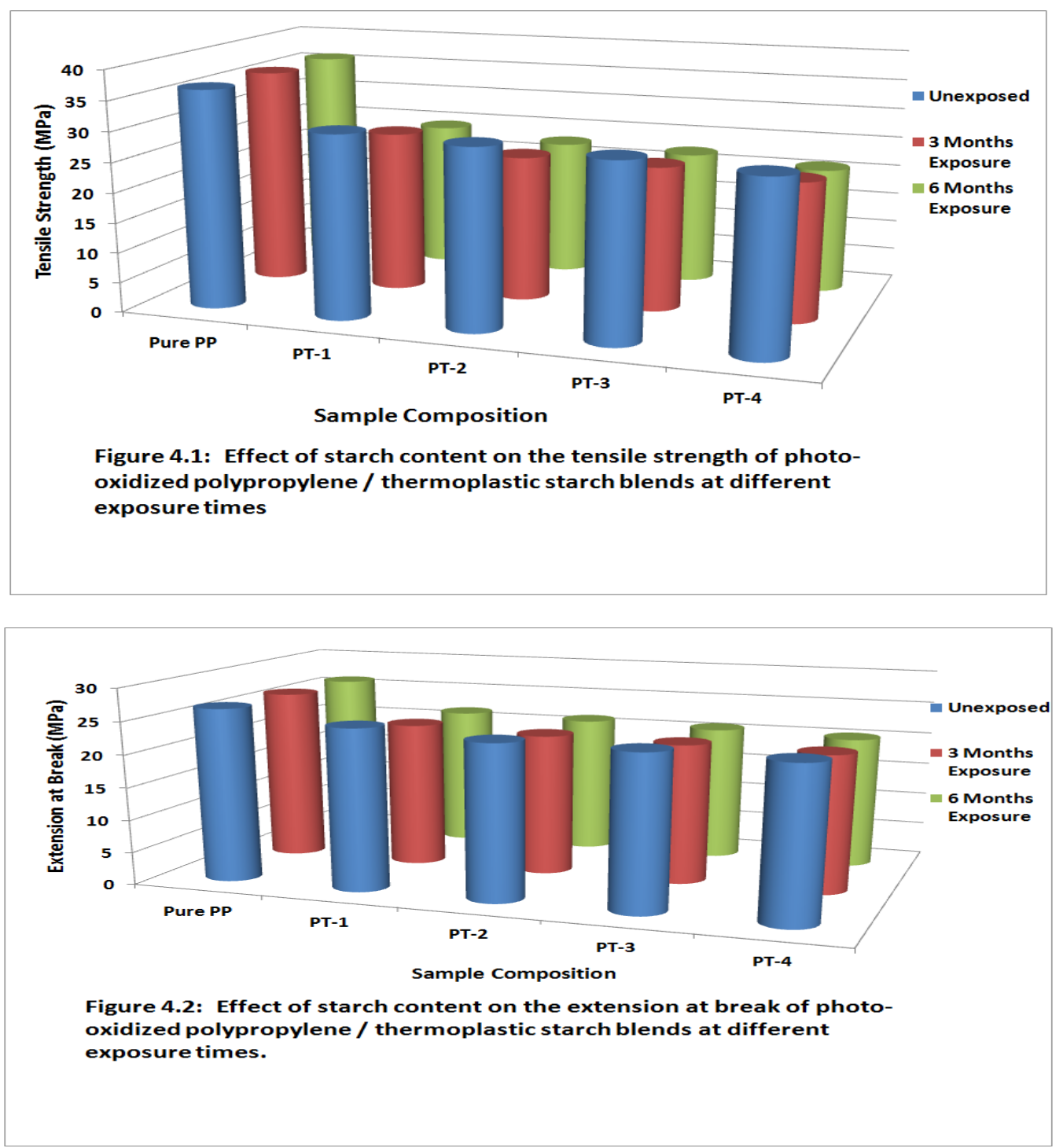


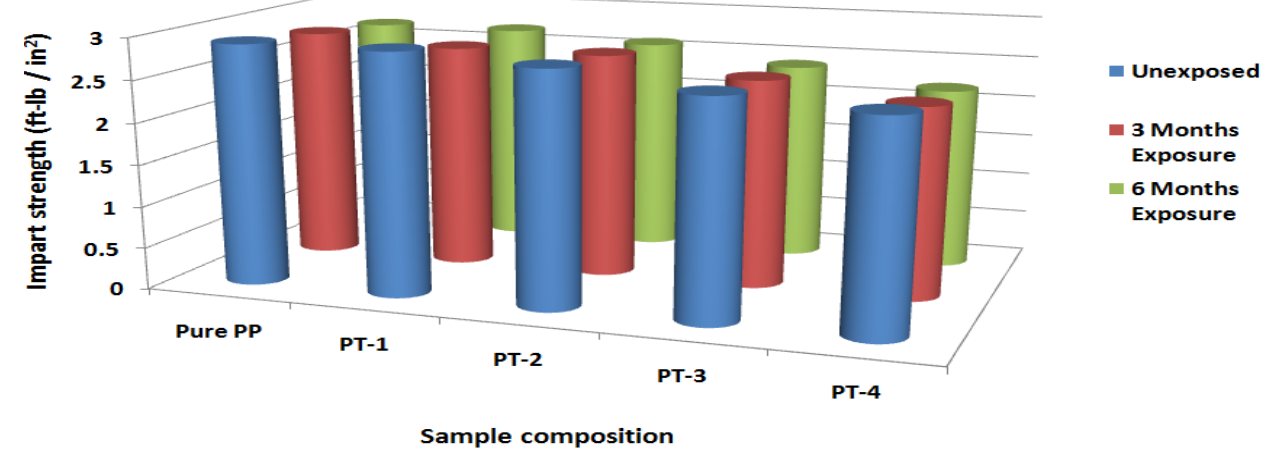

Figure 4.3. Effect of starch content on the impact strength of photoxidized polypropylene / thermoplastic starch blends at different exposure times.

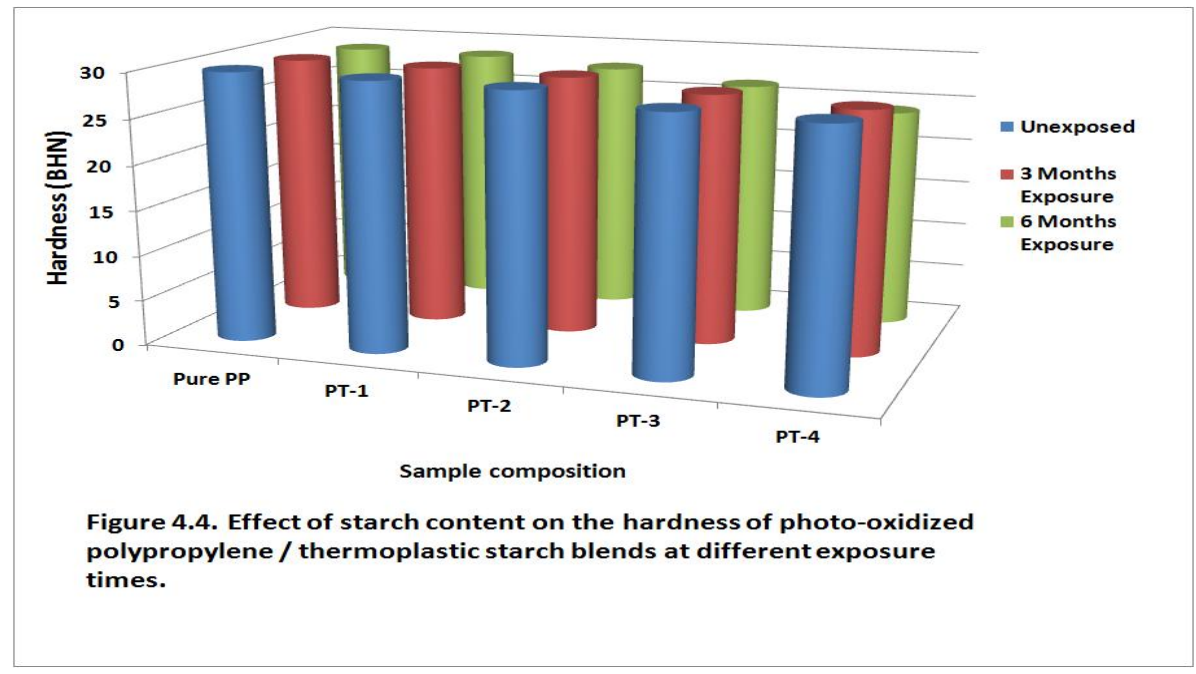

higher the thermoplastic starch content, the more the increase in the porosity of the PP matrix which allowed the permeation of light and oxygen through-out the inner part of the polypropylene matrix, thereby promoting the oxidation of the samples. Figures 4.1 to 4.4 show that when the thermoplastic starch content increased, the tensile yield strength, extension at break, hardness and impact strength of the photo-oxidized polypropylene / thermoplastic starch blend samples decreased, presumably because of incompatibility of polypropylene with the thermoplastic starch. It is possible that the inclusion of thermoplastic starch in the polypropylene matrix would have caused significant stress concentration which initiated fracture from the weak interface of the blend due to the poor interfacial adhesion, thus, resulting in reduced tensile yield strength and extension at break (Majid et al, 2010).

The figures also show that at any thermoplastic starch content in the blends considered, the tensile strength, extension at break, hardness and impact strength of the photooxidized blends decreased with increase in period of exposure of the samples to the atmosphere. Thakore et al (1999) who studied LDPE / potato starch blends reported that the tensile strength, toughness and elongation at break of the blends decreased with increase in starch content, a result similar to the findings of the present study. Similarly, Ratanakamnuan and Aht-Org (2006) in their studies reported that the inclusion of banana starch in photooxidized LDPE resulted to decrease in the tensile strength and elongation at break of the blends.

Effect of Compatibilizer Content on the Mechanical Properties of Photo-Oxidized Polypropylene / Thermoplastic Starch Blend Samples.

Data obtained on the tensile strength, extension at break, impact strength, and hardness of photo-oxidized polypropylene/thermoplastic starch blend samples containing polypropylene-graft-maleic anhydride as compatibilizer are illustrated graphically as shown in Figures $4.5-4.8$.

The tensile strength and extension at break of the photo-oxidized compatibilized samples were observed to decrease with increase in starch content at any given exposure time considered. Similarly, at any given starch content, the tensile strength and extension at break of the photo-oxidized compatibilized blend samples were found to decrease with increase in period of exposure. 
The Effect Of Benzophenone Photo-Initiator On Some Mechanical Properties Of Photo-Oxidized...
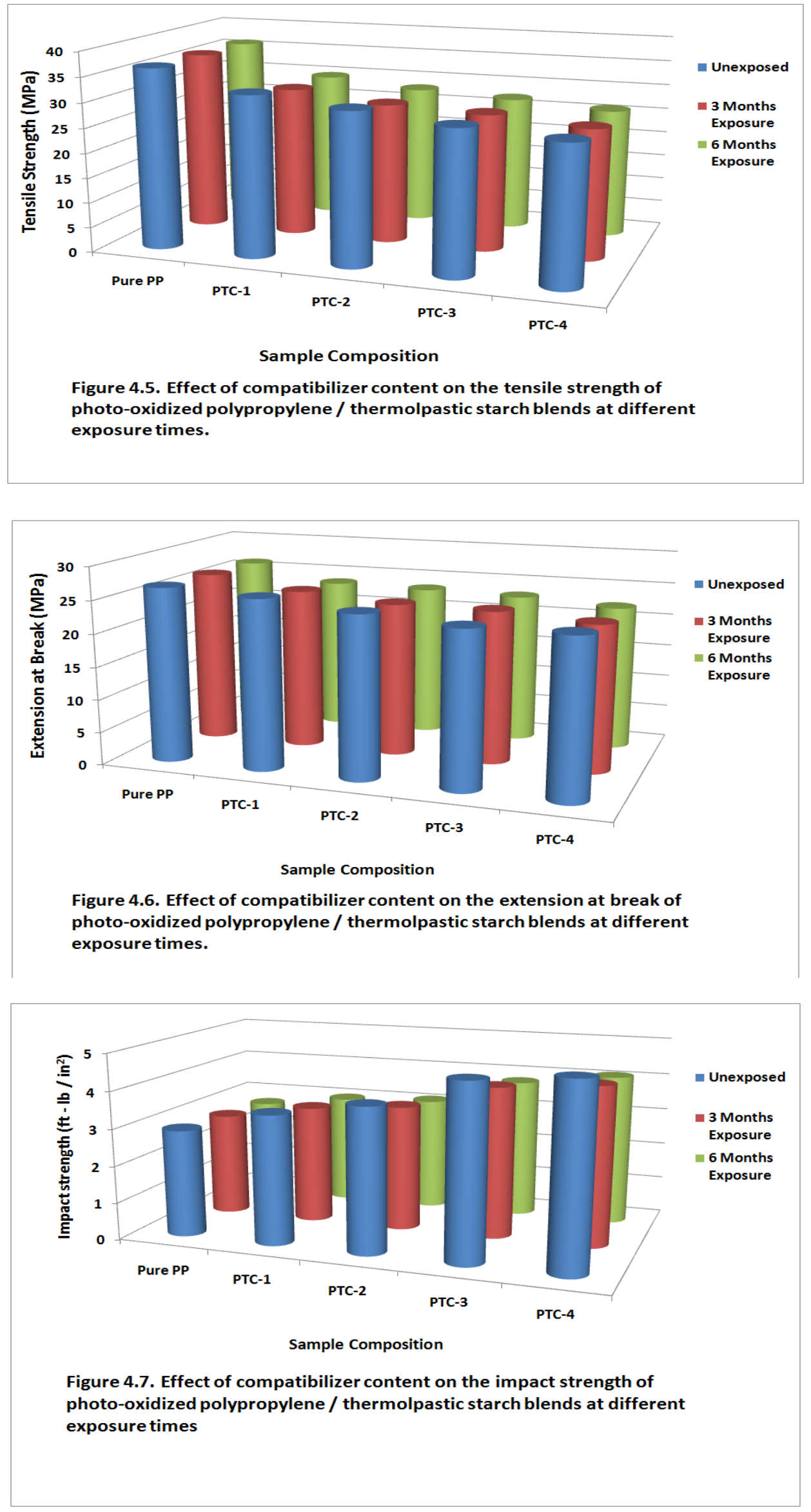


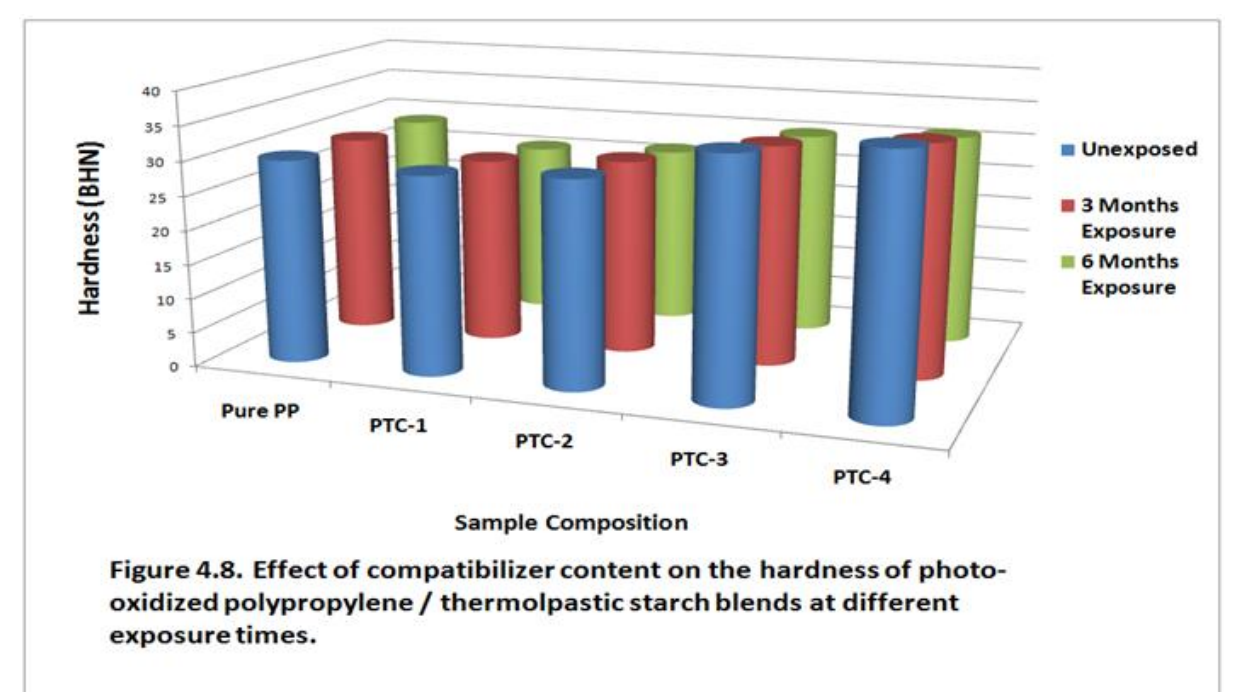

Consistent with the blend samples before being subjected to sunlight, the compatibilized blend samples exhibited greater tensile strength and extension at break compared to the uncompatibilized samples. The photooxidative degradation of polypropylene / thermoplastic starch blends with compatibilizer were found to increase in exposure times. However, as the exposure period increased, the tensile strength and extension at break of both compatibilized and uncompatibilized blends decreased continuously. It is believed that the PP-g-MA increased the adhesion between the polypropylene matrix, and the thermoplastic starch and which has a positive impact on the stress transfer, thereby reducing the chance of interfacial debonding, and leading to improved tensile properties. The result of this study further supports the assumption that the interaction between starch and PP-gMA was a chemical one between the hydroxyl groups in cassava starch and anhydride groups in PP-g-MA, because a polar interaction between them would not improve their properties to any significant extent.

Jifang et al (2007) carried out FTIR study on the photo-oxidation degradation of nano- $\mathrm{CaCO}_{3} / \mathrm{PP}$ composites by modifying the composites with three types of compatibilizers. The results they obtained showed that the photo-oxidation mechanism of $\mathrm{PP}$ was not altered by nano- $\mathrm{CaCO}_{3}$, but the rate of the oxidation was dramatically enhanced.

The impact strength of the compatibilized and uncompatibilized photooxidized blend samples depicted in Figure 4.14 showed that the impact strength of the samples increased progressively with increase in starch content at any exposure time considered. However, impact strengths were found to decrease with increase in the period of outdoor exposure from zero (0) to six (6) months at any given starch content considered.

The hardness of the compatibilized photooxidized blend samples were observed to exhibit two types of behaviour. First, while the hardness of the unexposed samples generally increased with increase in starch content, the compatibilized sample containing $10 \mathrm{wt} \%$ thermoplastic starch had lower impact strength than pure polypropylene. Secondly, for the blend samples subjected to three (3) to six (6) months of outdoor exposure, the samples containing 2 and 5 wt \% thermoplastic starch had lower impact strength than pure polypropylene. However, the impact strength increased with increase in starch content from 10 to $20 \mathrm{wt} \%$ starch content. It is interesting to note that generally, the impact strength of the blend samples containing 10 and $20 \mathrm{wt} \%$ of starch were higher than that of pure polypropylene.

Effect of Photoinitiator Content on the Mechanical Properties of Photo-Oxidized Polypropylene / Thermoplastic Starch Blend Samples.

Data on the tensile strength, extension at break, impact strength, and hardness of the photo-oxidized polypropylene/thermoplastic starch blend samples in the presence of photoinitiator (benzophenone) are illustrated graphically as shown in Figures $4.9-4.12$. The tensile strength and extension at break of the blend samples were observed to decrease with increase in exposure time at any starch content considered. The reduction in both the tensile strength and extension at break with increasing exposure time and benzophenone content is probably due to chain scission occurring during blend exposure to sunlight. Benzophenone can generate free radicals capable of breaking down the long polymer chains into shorter ones. As a result, the lowest tensile strength and extension at break were obtained from the PTPSCB-4 blend sample after being exposed for six months. These results mean that, after a certain period of exposure, the blend samples containing photosensitizer started losing their strength and became brittle (Majid et al, 2010).

Kadambanathan (2009) who investigated the photo-oxidative degradation of polypropylene (PP)/C20A nanocomposite containing MA-g-PP as a compatibilizer and two different photo initiators, ferrocene, and iron 
ricinoleate reported improved photo oxidative characteristics for the nanocomposites as compared to PP / clay nanocomposites. Property characterization of the composites showed that the PP nanocomposites showed slight decreases in tensile strength, tensile modulus and tear resistance as compared to the virgin polypropylene.

As shown in Figures 4.19 and 4.20, the impact strength of the compatibilized blend samples were generally less than those of the samples containing benzophenone at any given starch content and exposure time considered. In essence, the presence of benzophenone led to degradation of the blend samples resulting to the observed decreases in the extension at break, impact strength, and some tensile strengths of the exposed blend samples. However, for the compatibilized blend samples containing 2 and 5 wt \% starch, the hardness of the blend samples were found to be higher than those of compatibilized blends without benzophenone.
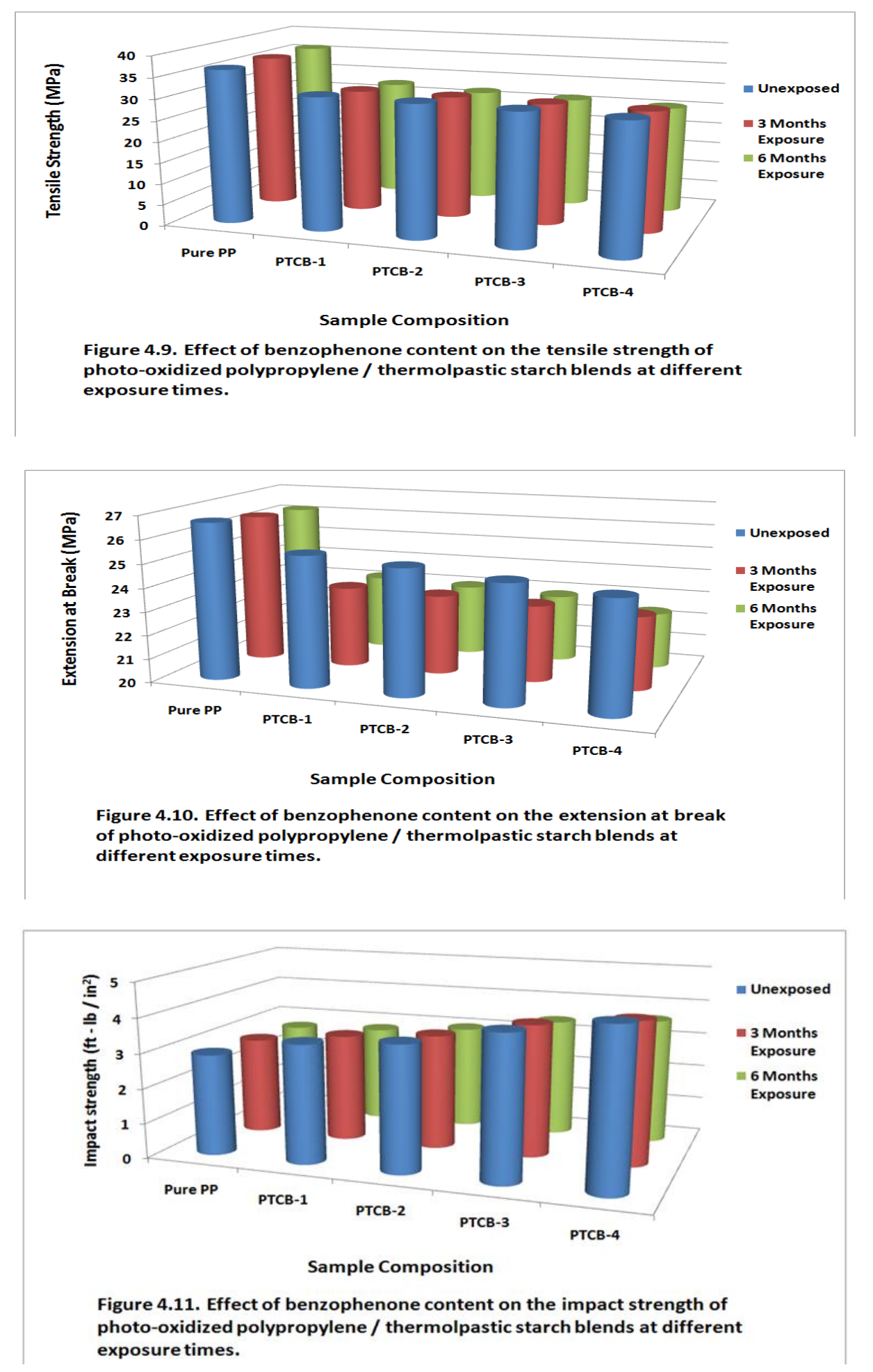


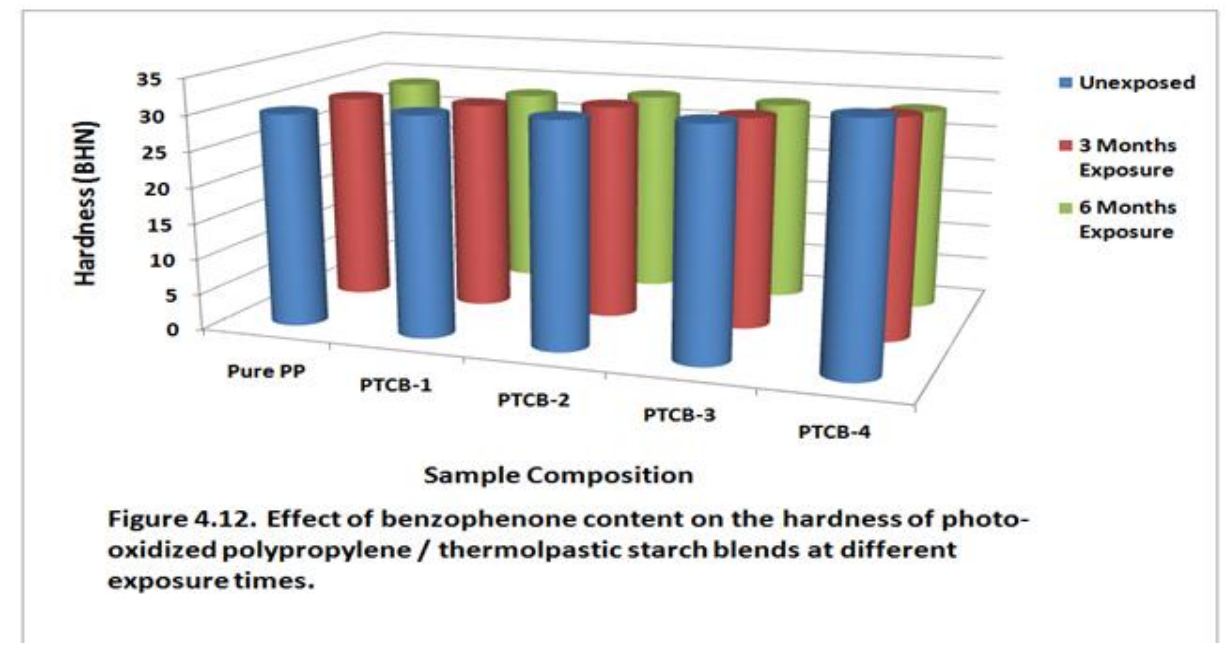

Weight Losses for Photo-oxidized Polypropylene / Thermoplastic Starch Blend Samples.

Data on the percentage weight losses of polypropylene / thermoplastic starch blends at varying thermoplastic starch content, compatibilizer, photoinitiator, and pro-oxidants, and exposure time in sunlight are illustrated graphically as shown in Figures 4.13-4.15. Pure polypropylene sampl exposed to sunlight in an open
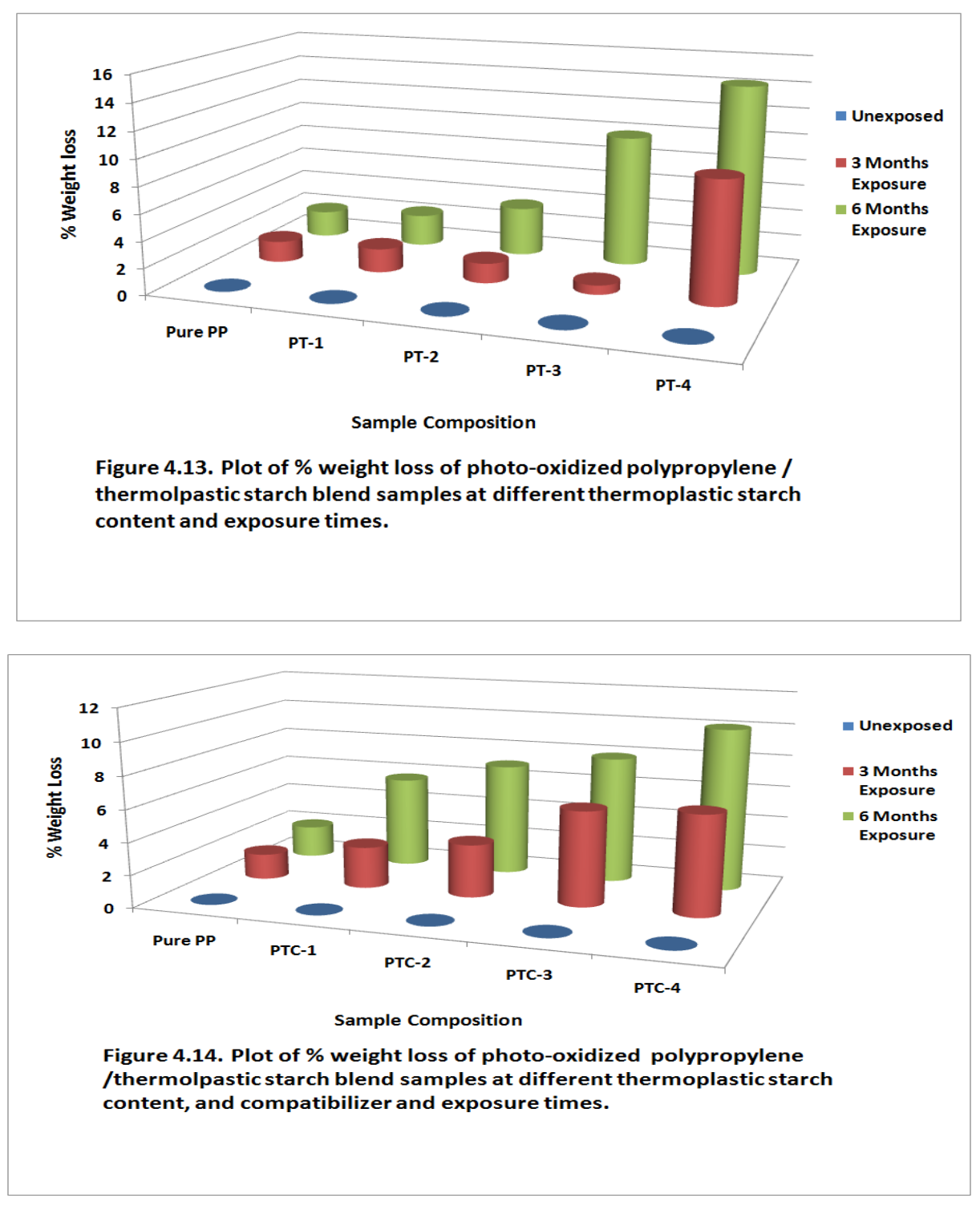


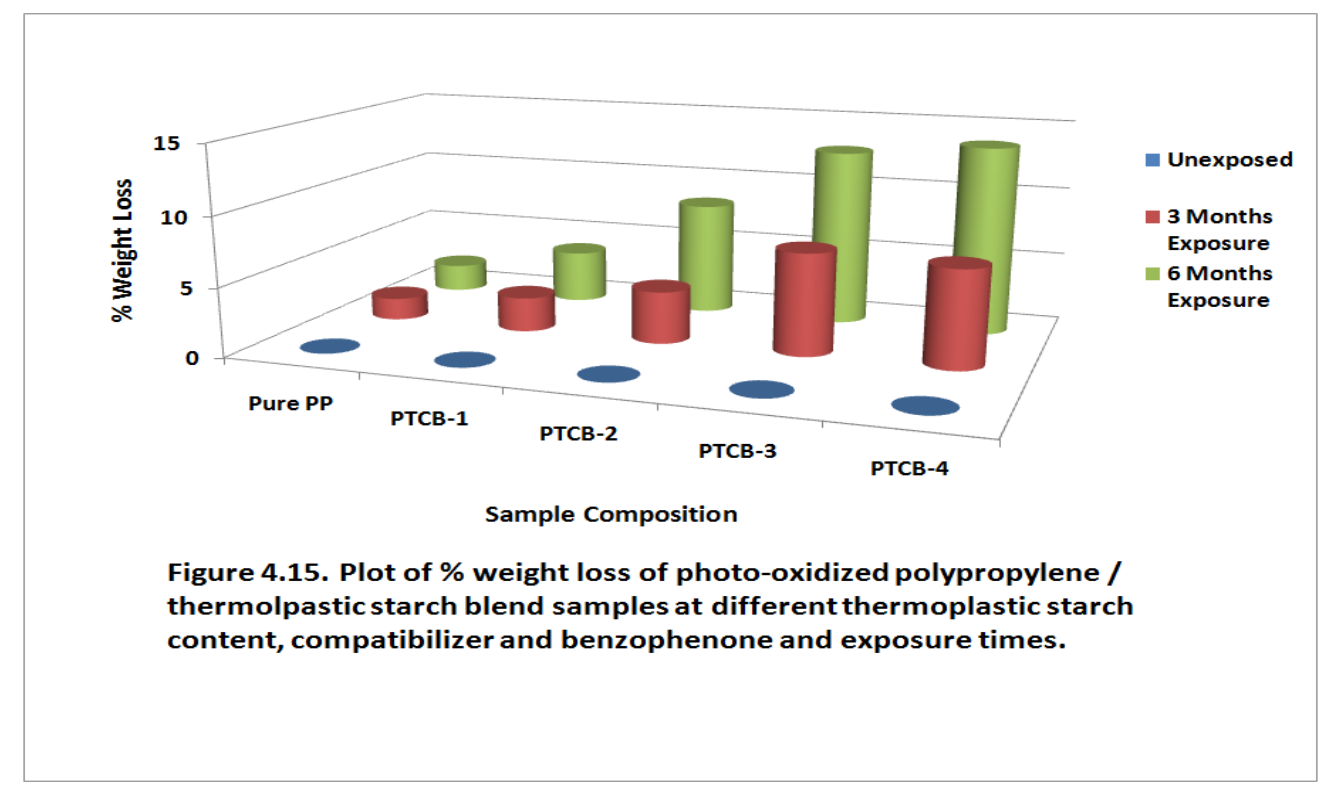

\section{CONCLUSION}

Benzophenone has been used as a photo-initiator to prepare blends of polypropylene / thermoplastic starch and its effect on some mechanical properties of photo-oxidized polypropylene / thermoplastic starch blends has been investigated. Experimental results obtained showed that the tensile strength, and extension at break of the photooxidized polypropylene / thermoplastic starch blended samples were found to decrease with increases in thermoplastic starch, and benzophenone content, while the impact strength, hardness, and weight losses of the blend samples increased with increases in the maleic- graft- anhydride polypropylene, and benzophenone contents as well as periods of exposure. This study reveals the potential use of benzophenone for improving the photo-oxidation of polypropylene / thermoplastic starch blends in future, and develops its niche in the scientific record.

\section{REFERENCE}

[1]. Abdul Khalil, H.P.S., Chow, W.C., Rozman, H.D., Ismail, H., Ahmad, M.N., and Kumar, R.N.. (2001). Polymer-Plastic Technology and Engineering 40(3): 249-263.

[2]. Ann-Christine Albertsson, Camilla Barenstedt, and Sigbritt Karlsson. (1992). Polymer Degradation and Stability Vol. 37 (2) pp 163-171.

[3]. Baljit. Singh and Nisha Sharma. (2008). Polymer Degardation and Stability. Vol 93 pp 561-584.

[4]. Cacciari, I., Quatrini, P., Zirletta, G., Mincione, E., Vinciguerra, V., and Lupattelli, P., (1993).. Applied Environmental Microbiology 1: 3695-3700.

[5]. Chun, K.S., Husseinsyah, S., and Osman, H. (2013a). Journal of Thermoplastic Composite Materials. ISSN: 0892-7057

[6]. Chun, K.S., Husseinsyah, S., and Osman, H. (2013b). Advance Material Research Journal. Vol, 747 pp 645-648.

[7]. Jifang, L., Rui, Y., Jian, Y., and Ying, L. (2007). Polymer Degradation and Stability 93(1): 84-89.

[8]. Kamble. A., Singh. V., Thomas. M., and John, N. (2011). Chemical Sciences Journal, Vol, 34, 1-9.

[9]. Majid, R.A., Ismail, H., and Razaina, M.T. (2010). Iranian Polymer Journal. Volume 19, Issue 7, 501-510.

[10]. N. Sharma, L.P. Chang., Y.L Chu., H.Ismail., U.S. Ishiaku., and Z.A Mohd Ishak. (2001). Polymer Degradation and Stability. Vol 71 pp 381-393.

[11]. Nawang, R., Danjaji, I.D., Ishiaku, U.S., Ismail, H., and Ishak, Z.A.M. (2001). Polymer Testing. 20(2): 167-170.

[12]. Ogah. A.O., and Afiukwa. J.N. (2011). Cont. J. of Biological Science. 5(1), pp. 20-25, 2011.

[13]. Omichi, H., Hagiwara, M., Asaro. and Araki, K. (1979). Journal of Applied Polymer Science. 24 (11), 2311-2319.

[14]. Park,J.M, Quang. S.T., Hwang. B.S., and Devries, K.L. (2006). Composite Science Technology. Vol. 66 pp 2686-2699.

[15]. Pushpadass, H. A., Kumar, A., Jackson, D.S, Wehling, R.L., Dumais, J.J., and Hanna, M, A. (2009). Starch-Starke, 61, 256-266.

[16]. Ratanakamuan, U., and Aht-Ong, D. (2006). Journal of Applied Polymer Science. Volume 100 Issue 4, 2725-2736.

[17]. Salmah, H., Marliza, M.Z., and Solvi.E. (2014). Advances in Materials Research, Vol. 3 No.3 pp 129-137.

[18]. Thakore, I.M., Iyer, S., Desai, A., Lele, A., and Devi, S. (1999). Journal of Applied Polymer Science, Volume 74, Issue 12, 2791 2802.

[19]. Wang, L., Shogren, R.L., and Carriere, C., (2000). Polymer Engineering and Science 40: 499-506.

[20]. Yang, J., Yu, J., and Ma, X.. (2006). Starch/Stärke 58: 330-337. 